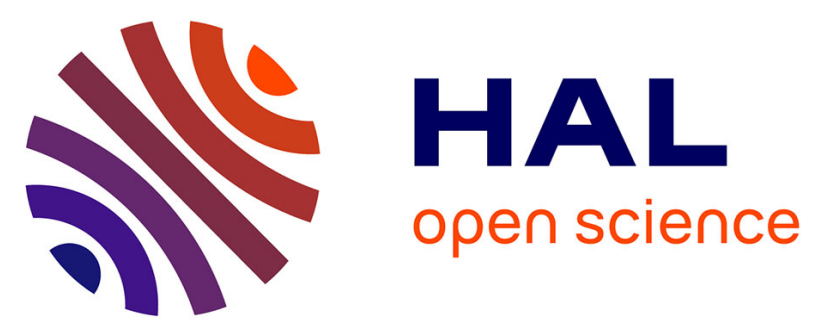

\title{
First evidence of superiority of Si nanonet field effect transistors over multi-parallel Si nanowire ones in view of electrical DNA hybridization detection
}

\author{
Thi Thu Thuy Nguyen, Maxime Legallais, Fanny Morisot, Thibauld \\ Cazimajou, Valérie Stambouli, Mireille Mouis, Bassem Salem, Céline Ternon
}

\section{To cite this version:}

Thi Thu Thuy Nguyen, Maxime Legallais, Fanny Morisot, Thibauld Cazimajou, Valérie Stambouli, et al.. First evidence of superiority of Si nanonet field effect transistors over multi-parallel Si nanowire ones in view of electrical DNA hybridization detection. Materials Research Express, 2019, 6 (1), pp.016301. 10.1088/2053-1591/aae0d5 . hal-01947795

\section{HAL Id: hal-01947795 \\ https: / hal.univ-grenoble-alpes.fr/hal-01947795}

Submitted on 7 Jan 2021

HAL is a multi-disciplinary open access archive for the deposit and dissemination of scientific research documents, whether they are published or not. The documents may come from teaching and research institutions in France or abroad, or from public or private research centers.
L'archive ouverte pluridisciplinaire HAL, est destinée au dépôt et à la diffusion de documents scientifiques de niveau recherche, publiés ou non, émanant des établissements d'enseignement et de recherche français ou étrangers, des laboratoires publics ou privés. 
PAPER

First evidence of superiority of Si nanonet field effect transistors over multi-parallel Si nanowire ones in view of electrical DNA hybridization detection

To cite this article: Thi Thu Thuy Nguyen et al 2019 Mater. Res. Express 6016301

View the article online for updates and enhancements.

\section{IOP ebooks}

Bringing you innovative digital publishing with leading voices

to create your essential collection of books in STEM research.

Start exploring the collection - download the first chapter of every title for free. 
PAPER

CrossMark

\title{
First evidence of superiority of Si nanonet field effect transistors over multi-parallel Si nanowire ones in view of electrical DNA \\ hybridization detection
}

PEVISED

5 September 2018

ACCEPTED FOR PUBLICATION

12 September 2018

PUBLISHED

3 October 2018

\author{
Thi Thu Thuy Nguyen ${ }^{1}$, Maxime Legallais ${ }^{1,2}$, Fanny Morisot $^{1,2}$, Thibauld Cazimajou $^{2}$, Valérie Stambouli $^{1}$ (D), \\ Mireille Mouis $^{2}$, Bassem Salem ${ }^{3}$ (i) and Céline Ternon ${ }^{1,3}$ (i) \\ 1 Univ. Grenoble Alpes, CNRS, Grenoble INP, LMGP, F-38000 Grenoble, France \\ 2 Univ. Grenoble Alpes, CNRS, Grenoble INP, IMEP-LaHC, F-38000 Grenoble, France \\ Univ. Grenoble Alpes, CNRS, LTM, F-38000 Grenoble, France \\ E-mail: celine.ternon@grenoble-inp.fr
}

Keywords: silicon nanowire, silicon nanonet, field-effect transistors, electrical characterizations, DNA detection, GOPS functionalization, semiconducting nanowire network

\begin{abstract}
Si nanonets (SiNN, networks of randomly oriented Si nanowires) and multi-parallel silicon nanowires (MP-SiNW) were integrated into field effect transistor using standard and low cost microelectronic technologies. The SiNN field effect transistors exhibit high initial ON-state current (in the range of $\left.10^{-7} \mathrm{~A}\right), \mathrm{I}_{\mathrm{ON}} / \mathrm{I}_{\mathrm{OFF}}$ ratio up to $10^{4}$ and rather homogeneous transfer characteristics. In contrast, the MP-SiNW ones present smaller modulation between $\mathrm{ON}$ and OFF currents, higher $\mathrm{I}_{\mathrm{OFF}}$ and more scattered electrical characteristics. In view of DNA hybridization detection, a simple and eco-friendly functionalization process with glycidyloxypropyltrimethoxysilane (GOPS) was used to covalently graft single strand DNA probes on both SiNN and MP-SiNW devices. Validated by fluorescence measurement, DNA hybridization leads to a systematic decrease of ON-state current of SiNN devices. In addition, SiNN-based sensors exhibit more homogeneous and reproducible current variation in response to DNA hybridization step as compared to MP-SiNW configuration. This result highlights the better sensing performances of SiNN FETs as compared to MP-SiNW ones and emphasizes the SiNN potential for label-free detection of DNA.
\end{abstract}

\section{Introduction}

The integration of nanostructured materials (nanotubes, nanowires, nanoparticles) in biological sensors as sensitive elements has been particularly addressed in the last decades [1-5]. Indeed, thanks to their high surfaceto-volume ratio and large surface area, these nanostructures offer larger functionalized surfaces, thus more probe-target recognitions as compared to thin-film materials. Among these strategies, SiNWs have been particularly developed for electrical field-based sensors to detect numerous biomolecules: proteins [6], nucleic acids [7], or viruses [8]. Main advantages of SiNWs can be listed as: the mastered elaboration approach allowing a good control of morphology and doping level $[6,9,10]$, the comparable sizes with biological macromolecules which facilitate the functionalization and offer label-free, real-time and ultrasensitive detection to subfemtomolar detection limits [11-13]. However, the mass production of bottom-up SiNW-based sensing devices remains an ongoing challenge, due to two disadvantages: the expensive and complex integration technology, and the lack of reproducibility in electrical performances from one NW device to another [14]. To overcome such issues, a new structure has been developed, called nanonet (Nanostructured Network) in which the nanowires are randomly oriented. Several advantages make nanonets promising candidates for sensing applications: electrically active, tolerant to faults thus more reproducible in physical properties as compared to single NW or nanotube [15-19]. In addition, these networks can be readily functionalized to get new desired properties which open opportunities for biosensing applications [20-22]. 


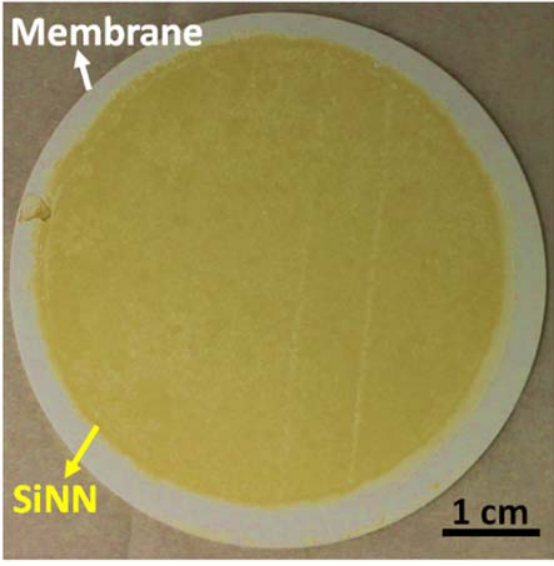

(a)

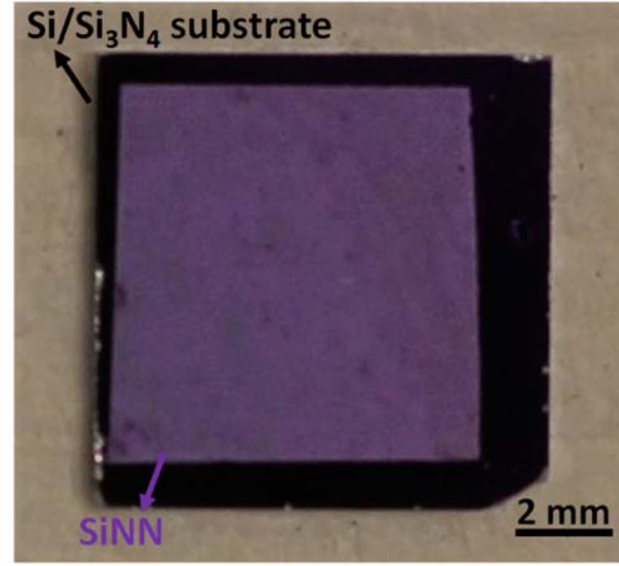

(b)

Figure 1. (a) Nanonet assembled on a nitrocellulose membrane, (b) Nanonet transferred onto 200-nm-thick $\mathrm{Si}_{3} \mathrm{~N}_{4}$ covered silicon substrate.

This work aims to develop DNA sensing demonstrators using SiNN field-effect transistors (SiNN FETs). In principle, these devices allow to measure the variation of nanonet conductance caused by the recognition between DNA probes and targets (called hybridization). As compared to current DNA sensors using SiNW, the SiNN-based ones are expected to be cheaper because they do not require use of complex and time-consuming tools. To achieve this goal, it is mandatory to successfully functionalize the SiNN with strongly attached DNA probes on nanowire surface in order to enable the DNA hybridization. The aminopropyltriethoxysilane (APTES) is the most currently used organosilane to functionalize SiNW because its amine function can easily react with a cross-linker to allow DNA probe grafting. Indeed, APTES functionalization results in an amineterminated surface. Glutaraldehyde is usually used as the cross-linking agent. Its two terminal aldehyde groups can easily react with the $\mathrm{NH}_{2}$ from APTES and DNA via the imine formation [20]. However, the glutaraldehyde is a toxic component and this cross-linking step is time consuming [22]. For these reasons, we have performed another functionalization process using glycidyloxypropyltrimethoxysilane (GOPS). This one enables fast and direct grafting of the $\mathrm{NH}_{2}$ termination of DNA probes on the epoxy termination of GOPS. The DNA hybridization with complementary single strand DNA targets on the sensor will be validated by fluorescence measurement.

In this paper, we report firstly the morphological and electrical characterizations of SiNN and as-fabricated SiNN field-effect transistors. Secondly, we discuss about the difference between SiNN- and multi-parallel SiNW-devices. Thirdly, the DNA hybridization detection was registered as changes in electrical responses of configured FETs, which was also validated by conventional fluorescence measurement. Finally, the response to DNA hybridization of the two kinds of sensing devices will be revealed and interpreted.

\section{Experimental section}

\subsection{Nanonet formation}

The silicon nanowires were grown on Si substrate via vapor-liquid-solid (VLS) mechanism using chemical vapor deposition technique, with the presence of gold nanoparticles as metal catalyst and silane $\left(\mathrm{SiH}_{4}\right)$ as gaseous silicon precursor. The NWs are non-intentionally p-doped with the doping concentration estimated at $10^{16}$ at. $\mathrm{cm}^{-3}$ as deduced from four-point probe measurement carried out on single NWs [23]. After growth, these SiNWs were dispersed by sonication into deionized water for $5 \mathrm{~min}$. This suspension was then characterized by absorption spectroscopy, afterwards diluted until its absorbance at $400 \mathrm{~nm}$ reaches 0.06 . This method guarantees a reproducible nanowire amount from one suspension to another for a given volume of NW suspension. For nanonet elaboration, a volume of $28 \mathrm{ml}$ of such NW suspension was vacuum filtered through a nitrocellulose membrane, as shown in figure 1(a), forming nanonets with a surface density of $6.5 \times 10^{7} \mathrm{NWs.cm}{ }^{-2}$. Indeed, the $\mathrm{NN}$ density $\left(\mathrm{d}_{\mathrm{NN}}\right)$ is related to the filtered volume $\left(\mathrm{V}_{\text {filtered }}\right)$ of $\mathrm{NW}$ suspension as follows: $\mathrm{d}_{\mathrm{NN}}=2.34 \times \mathrm{V}_{\text {filtered }} \times 10^{6}\left(\mathrm{NWs.cm}{ }^{-2}\right)$ [24].

For their integration into transistors, this filter was cut into coupons with a compatible size for substrate dimension $\left(1 \times 1 \mathrm{~cm}^{2}\right.$ in this work). The $\mathrm{NN}$ was then transferred onto silicon substrate covered with $200-\mathrm{nm}$ thick $\mathrm{Si}_{3} \mathrm{~N}_{4}$, as shown in figure 1(b), by filter dissolution in acetone bath for $35 \mathrm{~min}$. 


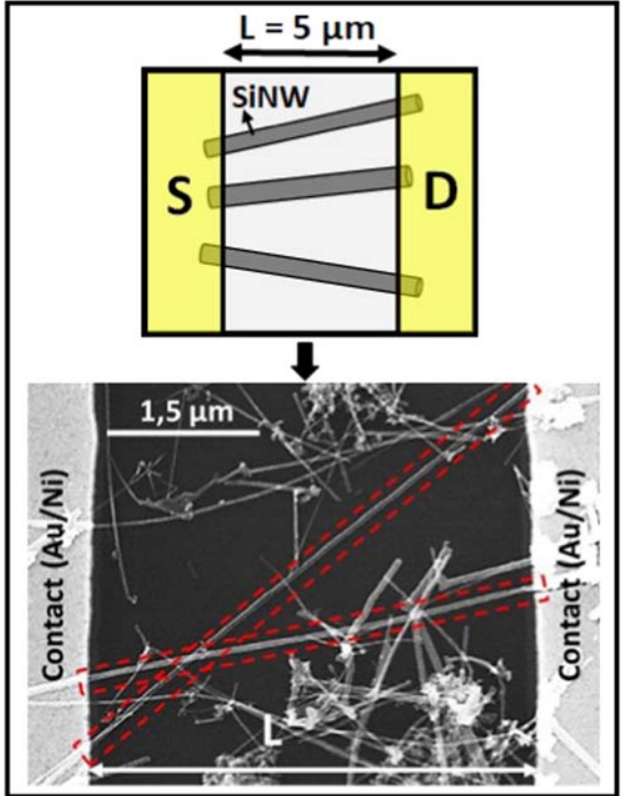

(a)

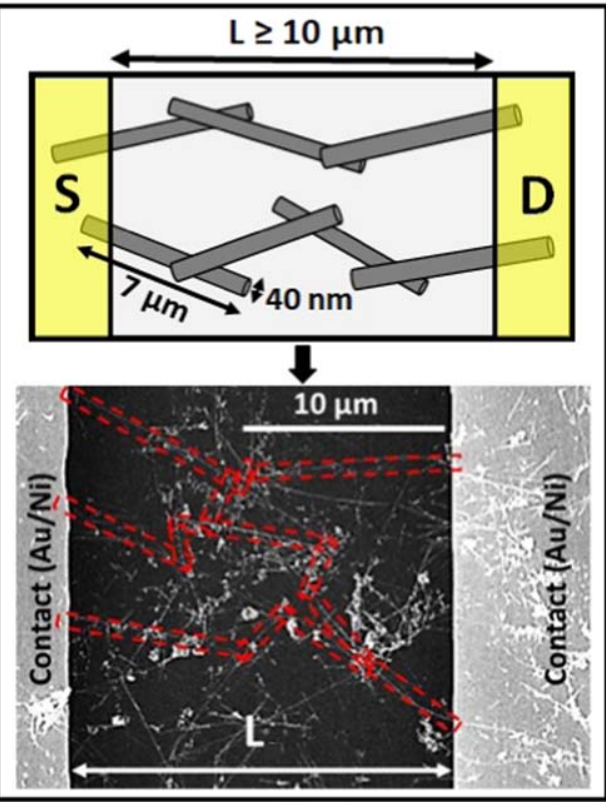

(b)

Figure 2. Two configurations of field effect transistors: (a) MP- SiNW FETs, (b) SiNN FETs. The nanowires have an average diameter of $40 \pm 7 \mathrm{~nm}$ and a mean length of $7 \pm 3 \mu \mathrm{m} ; \mathrm{S}=$ source, $\mathrm{D}=$ drain, the two electrodes of the FET; gate is on the back side.

Our process revealed several advantages. Firstly, the self-assembly technique performing nanonet is at a time simple, rapid, at room temperature, low cost but highly efficient. Secondly, we can precisely control the nanonet density by varying the filtered volume of NW suspension, for example in this work, $28 \mathrm{ml}$ was chosen. Third, the nanonet can be easily transferred onto larger substrates by increasing the size of filter, indicating its up-scalability to large areas. Finally, this can be done with any desired substrate, from rigid to flexible, transparent to opaque, demonstrating its potential for various application fields.

\subsection{Fabrication of MP-SiNW and SiNN FETs}

After their transfer onto highly doped silicon substrate covered with 200 -nm-thick $\mathrm{Si}_{3} \mathrm{~N}_{4}$, the NN was immersed into a Buffer Oxide Etching (BOE) solution for $30 \mathrm{~s}$, and then immediately annealed at $400^{\circ} \mathrm{C}$ for $1 \mathrm{~min}$ in nitrogen. These steps allow two sequential effects to happen in the nanowire network: the removal of the native silicon dioxide surrounding the NWs by fluoride acid action, followed by the sintering of NW/NW junctions by annealing to create conducting paths between the wires. This sintering process, patented by our group, is simple and efficient to form and stabilize conducting polycrystalline silicon nanowire networks [16]. For the integration of such sintered nanonet into FETs, the Si substrate was used as the back gate while the $\mathrm{Si}_{3} \mathrm{~N}_{4}$ served as gate dielectric layer of transistors. In view of depositing source and drain contacts, photolithography process was employed to define electrode pads through a mask. After photoresist development and hard baking, a second BOE treatment was applied in order to remove the native oxide shells surrounding NWs. This step was immediately followed by the evaporation of two consecutive layers of 100-nm-thick nickel and 50-nm-thick gold. Lift-off was afterwards performed to define source and drain electrodes. Finally, these nanonet devices were annealed at $400{ }^{\circ} \mathrm{C}$ for $1 \mathrm{~min}$ in nitrogen in order to promote the silicide formation between Ni and SiNWs, thus, an Ohmic contact between the nanonet and electrodes. This process, consisting of several standard microelectronic techniques, has been detailed elsewhere [23, 24].

Depending on the channel length (L) compared to the SiNW one, two kinds of FET devices were considered. On the one hand, transistors with a channel shorter than the NW length ( $\mathrm{L}=5 \mu \mathrm{m}$, figure 2(a)) were considered as MP-SiNW FETs. In this configuration, charge carriers can flow from source to drain without crossing any NW/NW junction. On the other hand, devices with $\mathrm{L} \geqslant 10 \mu \mathrm{m}$ (figure 2(b)), where charge carriers should pass through several NW/NW junctions, were considered as nanonet-based devices. The simultaneous fabrication of both types of devices on the same substrate allows us to reveal the differences in electrical behavior at each step of DNA detection between multi-parallel SiNW devices and SiNN ones. The number of devices characterized in this work is shown in table 1.

In view of DNA detection, these devices will be functionalized using GOPS in order to graft single strand DNA probes onto SiNN and SiNW surface. The strategy applied is as follows: (i) DNA hybridization by exposing the biofunctionalized SiNN and SiNW FETs to complementary DNA targets, (ii) fluorescence measurement in 
Table 1. Number of measured MP-SiNW FETs and SiNN FETs depending on the channel length.

\begin{tabular}{lcc}
\hline Devices & $\begin{array}{c}\text { Channel } \\
\text { length }(\mu \mathrm{m})\end{array}$ & $\begin{array}{c}\text { Number of measured } \\
\text { devices }\end{array}$ \\
\hline MP-NW FETs & 5 & 7 \\
NNFETs & 10 & 10 \\
& 15 & 10 \\
& 20 & 10 \\
\hline
\end{tabular}

order to validate the above DNA recognition and hybridization, (iii) electrical measurement of the change caused by DNA hybridization on device characteristics.

\subsection{Functionalization process}

The SiNN and MP-SiNW devices were functionalized simultaneously using GOPS via several steps, including hydroxylation, silanization and covalent DNA probe grafting. The GOPS, single strand DNA probes and DNA targets were bought from Sigma-Aldrich.

\subsubsection{Hydroxylation}

This step is necessary to create hydroxyl $(-\mathrm{OH})$ groups that allow covalent binding of the functional organosilane on the nanonet surface. This step was performed using an air plasma for 4 min with RF power of $12 \mathrm{~W}$ and pressure fixed at 0.4 Torr.

\subsubsection{Silanization}

The silanization step was performed via GOPS vapor deposition on nanonet surface in order to provide epoxy groups which enable the direct grafting of $\mathrm{NH}_{2}$ terminated DNA probes onto semiconductor surface [22]. This step was divided into two sub-steps: (i) deposition of GOPS in vapor phase, (ii) GOPS polymerization on nanonet. For this, the sample, after being placed in a Teflon beaker, was put into a glove bag to ensure a dry atmosphere with humidity as low as $5 \%$. A volume of $150 \mu \mathrm{l}$ of GOPS was then delivered. After closing tightly the lid of the Teflon beaker, the sample was annealed at $100{ }^{\circ} \mathrm{C}$ for $1 \mathrm{~h}$ to promote the evaporation of GOPS and its condensation onto NN surface. Finally, the polymerization of GOPS on nanonet as well as the removal of remaining water were achieved by an other annealing at $135^{\circ} \mathrm{C}$ for $1 \mathrm{~h}$ in air. Such GOPS functionalization allows direct grafting of DNA as epoxy groups and amines can directly react together. As a consequence, there is no more need for the cross-linking step, which is compulsory in the case of classical functionalization using APTES. Our GOPS-based process is thus ecofriendly and time-saving as compared to commonly used APTESbased one.

\subsubsection{DNA probe grafting}

The single strand 5' $-\mathrm{NH}_{2}$-C6-TTTTTGATAAACCCACTCTA-3' DNA strands were used as model molecules. After dilution in a sodium phosphate solution $(150 \mathrm{mM})$, the DNA $(10 \mu \mathrm{M})$ was locally deposited in droplet $(1 \mu \mathrm{L})$ on the surface. The sample was then incubated for $30 \mathrm{~min}$ in a humid chamber at $60{ }^{\circ} \mathrm{C}$, and exposed to air at room temperature overnight. At this step, the Si nanonets were functionalized with single strand DNA probes and the DNA sensors based on these nanonets were ready for use.

\subsubsection{DNA hybridization}

The hybridization was carried out using complementary DNA targets (5'-CATAGAGTGGGTTTATCCA-3') labeled with a cyanine (Cy3) fluorescent dye. A $2 \mu \mathrm{M}$ concentration was used for the first demonstration. Although our work finally aims to develop the DNA hybridization techniques without any label, the use of Cy3 labeled DNA target is advantageous because it allows to validate the DNA hybridization via fluorescence measurement. These DNA targets $(2 \mu \mathrm{M})$, diluted in a hybridization buffer solution (NaCl: 0.5 M, PBS: $0.01 \mathrm{M}$ ), were spread on the whole nanonet surface with the help of a hybrislip paper. The sample was then placed in a humid chamber for $45 \mathrm{~min}$ at $42^{\circ} \mathrm{C}$. After this incubation time, it was intensively rinsed, two times and for $2 \mathrm{~min}$, in saline-sodium citrate (SSC) buffer $(2 \times$ for the first time and $0.2 \times$ for second one) to remove all adsorbed DNA targets from the surface. The rinsing was continued by dipping the sample into deionized water for a few seconds. The hybridization was finally accomplished after drying the sample with nitrogen. After this step, both single-strand probes and probe/target double-strand DNAs are simultaneously present at SiNW or SiNN surface. 


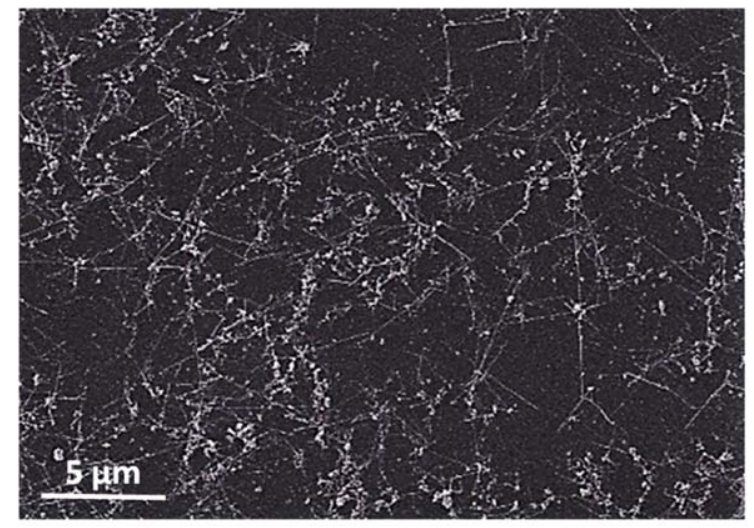

(a)

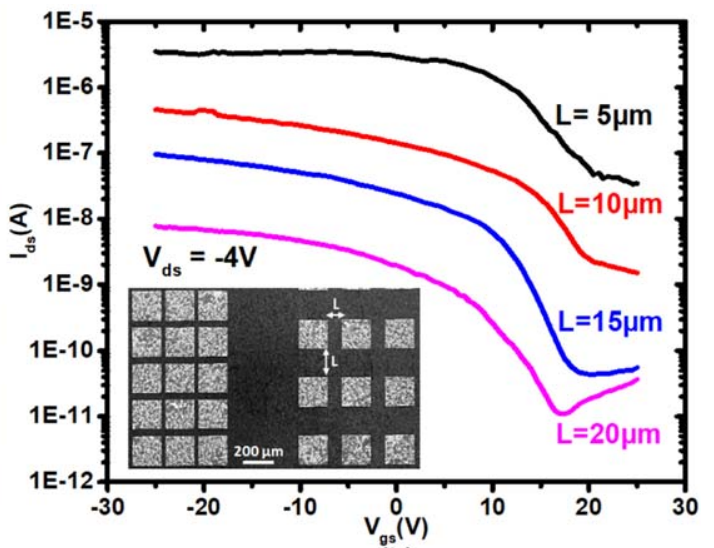

(b)

Figure 3. (a) SEM image of SiNW network elaborated from $28 \mathrm{ml}$ of NW suspension and transferred onto $\mathrm{Si}_{/} / \mathrm{Si}_{3} \mathrm{~N}_{4} \mathrm{substrate},(\mathrm{b})$ Transfer characteristics of FETs with L ranging from $5 \mu \mathrm{m}$ to $20 \mu \mathrm{m}$.

\subsection{Characterization techniques}

The morphology of the nanonets and field-effect devices was evaluated using scanning electron microscopy (Zeiss Ultra + Microscope). The electrical characterizations of FETs were performed using a typical probe station (Karl Süss station controlled by a HP4155A analyzer) in which we can apply needed voltage to device electrodes then measure the current in the channel. The measurements were carried out at room temperature and in dark environment. DNA hybridization was checked using a fluorescence microscope.

\section{Results and discussion}

\subsection{Morphological and electrical characterization of as-fabricated MP-NW and NN FETs}

The morphology of nanonet after processing is shown in figure 3(a). A rather homogeneous distribution of the NW was obtained, that indicates a successful transfer. This observation allows confirming several advantages of our process. With a simple, rapid, room temperature and low-cost process, good homogeneity of the Si nanowire network was achieved.

The typical transfer characteristics of four FETs with $\mathrm{L}=5,10,15,20 \mu \mathrm{m}$ after fabrication are reported in figure 3(b). The drain current $\left(\mathrm{I}_{\mathrm{ds}}\right)$ is plotted in logarithmic scale, as a function of gate voltage $\left(\mathrm{V}_{\mathrm{gs}}\right)$ for a constant drain voltage $\left(\mathrm{V}_{\mathrm{ds}}\right)$ chosen in the linear regime of operation. As one can see, the multi-parallel SiNW FET $\left(\mathrm{L}=5 \mu \mathrm{m}\right.$ ) shows small modulation between $\mathrm{ON}$ and OFF-state currents ( 2 orders of magnitude) and high $\mathrm{I}_{\mathrm{OFF}}$ (3.4.10 $\left.{ }^{-7} \mathrm{~A}_{\text {at }} \mathrm{V}_{\mathrm{gs}}=25 \mathrm{~V}\right)$. In contrast, the SiNN FETs $(\mathrm{L}=10-20 \mu \mathrm{m})$ exhibit reasonably high ON-state current (from $10 \mathrm{nA}$ to $1 \mu \mathrm{A}$ when $\mathrm{L}$ varies from 20 to $10 \mu \mathrm{m}$ ), low OFF-state one (down to $10 \mathrm{pA}$ at $\mathrm{V}_{\mathrm{gs}}=20 \mathrm{~V}$ for $\mathrm{L}=15$ and $20 \mu \mathrm{m}$ ), corresponding to an interesting $\mathrm{I}_{\mathrm{ON}} / \mathrm{I}_{\mathrm{OFF}}$ ratio up to $10^{4}$. In view of statistical analysis, the measurement of several devices with similar channel length was performed. The results obtained with $\mathrm{L}$ from 5 to $20 \mu \mathrm{m}$ are displayed in figure 4 . The MP-SiNW FETs $(\mathrm{L}=5 \mu \mathrm{m})$ show scattered characteristics while the SiNN ones exhibit a statistical variability which can be considered as reasonably low for nanowire-based devices. Finally, as expected, the ON-state current is lower with longer channels; but interestingly, the variability tends to decrease when channel length increases.

\subsection{DNA hybridization detection on SiNN FETs by fluorescence measurement}

Thanks to Cy3-labelled complementary DNA targets, the functionalization process has been validated using fluorescence detection upon hybridization. As shown in figure 5, no fluorescence appears on the metallic pads because of two effects: first, the functionalization process is less efficient on gold, second, being a mirror, destructive optical interferences appear on the metallic surface. A clear contrast in fluorescence is observed between the nanonet surface without DNA probes (which appeared dark) and the region where DNA probes were grafted (which exhibited a brighter fluorescence). This signal confirms the presence of Cy3 labeled DNA targets on the NN functionalized with probes, and hence a successful DNA hybridization. In addition, this contrast helps us to determine the hybridized devices which is essential to compare their electrical characteristics before and after DNA hybridization. 


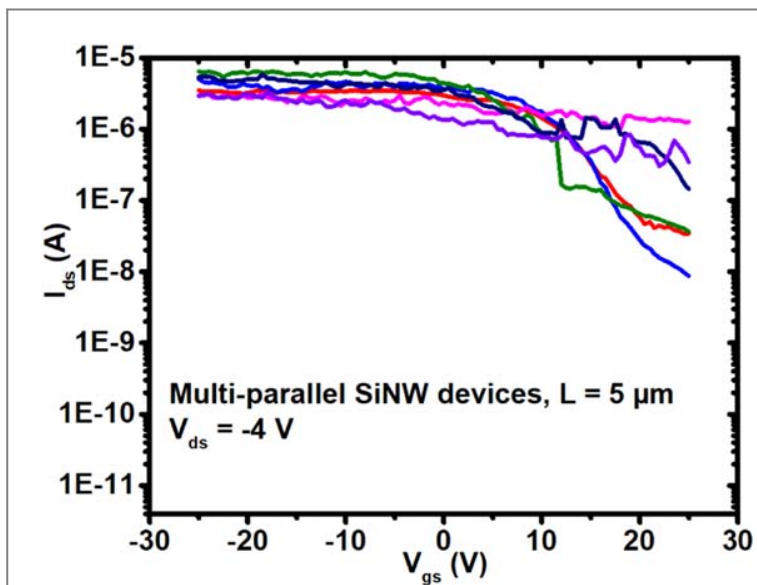

(a)

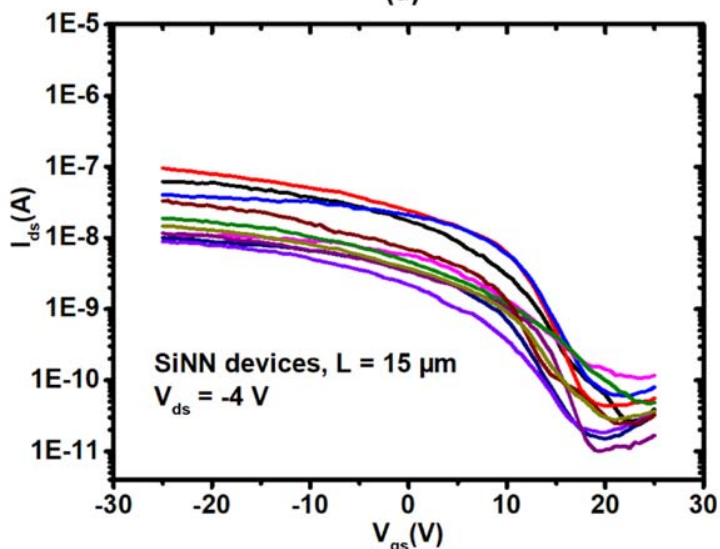

(c)

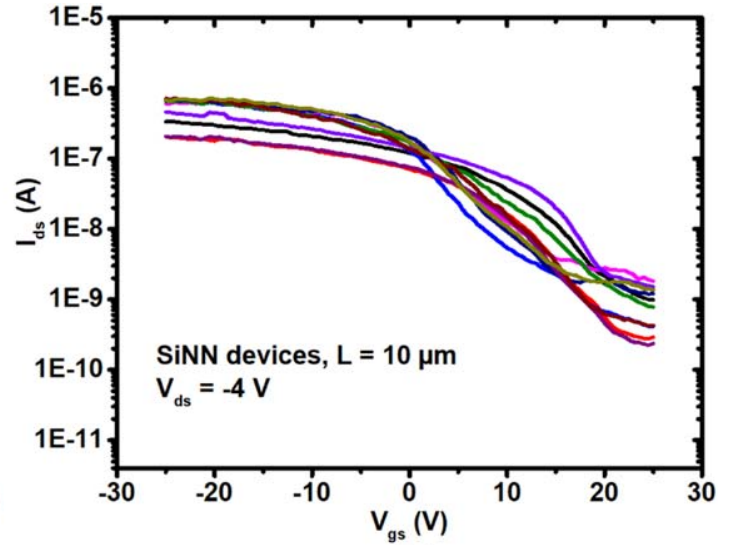

(b)

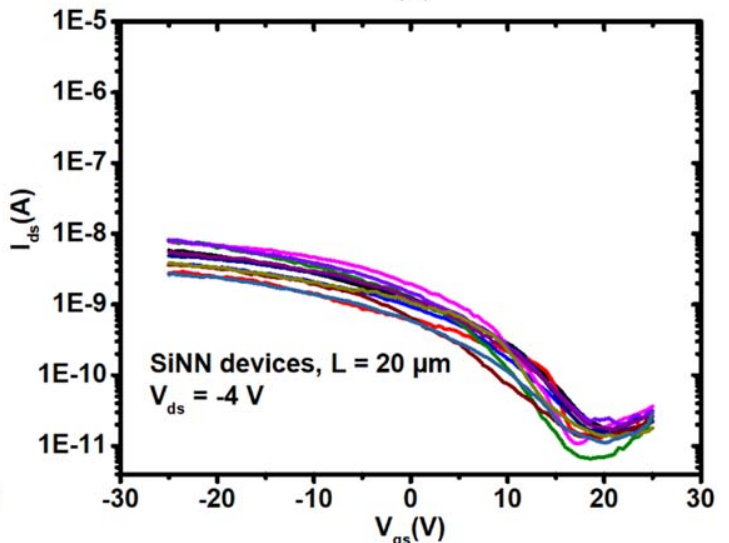

(d)

Figure 4. Transfer characteristics of FETs with: (a) $\mathrm{L}=5 \mu \mathrm{m}$, (b) $\mathrm{L}=10 \mu \mathrm{m}$, (c) $\mathrm{L}=15 \mu \mathrm{m}$, (d) $\mathrm{L}=20 \mu \mathrm{m}$
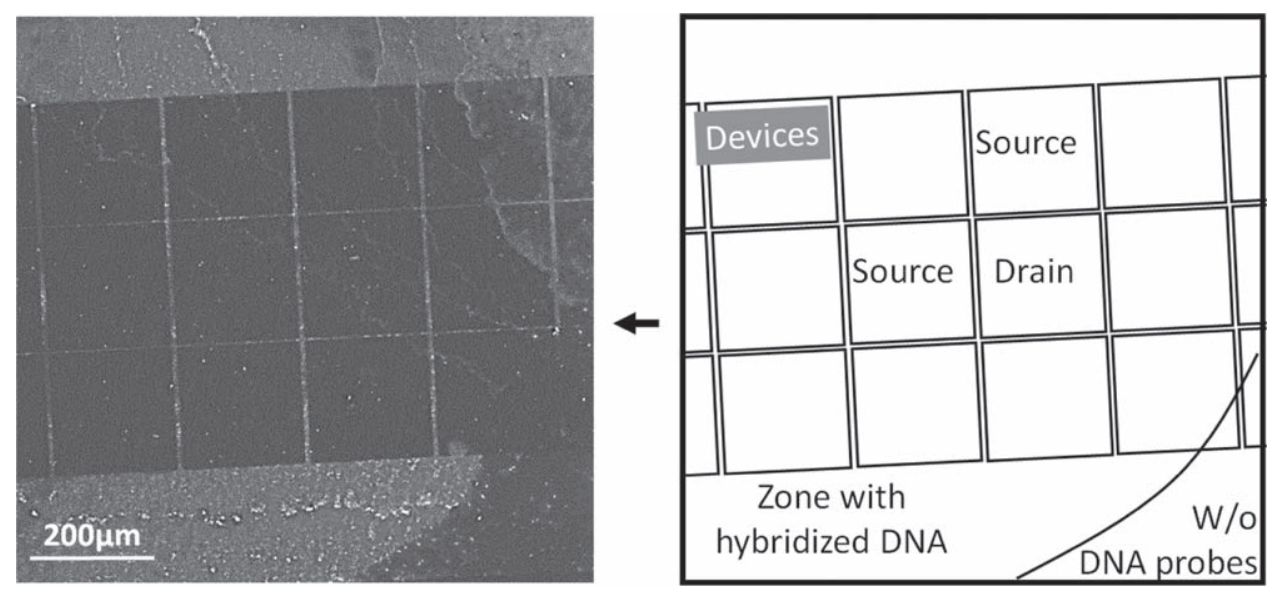

Figure 5. Florescence microscopy image of FETs after DNA hybridization using Cy3 labelled DNA targets with a sketch for better clarity (W/o = without).

\subsection{Electrical characteristics of SiNN-based DNA sensors}

Figure 6(a) displays the transfer characteristics of a SiNN FET with $\mathrm{L}=15 \mu \mathrm{m}$ before and after DNA hybridization. A significant decrease of ON-state current was observed after DNA hybridization on the nanonet. Such a decrease upon hybridization is quite surprising as the NN are p-type and DNA is negatively charged. It may be originated from the potential scattering of charge carriers by the grafted molecules at the channel surface which causes the decrease of mobility, thus, the current [25]. In addition, as GOPS functionalization was used here for the first time, such evolution could be related to the intermolecular cross-linking of GOPS molecules as reported by Pasha and Haick for another silane [26]. Despite the surprising variation, experimental results on 10 


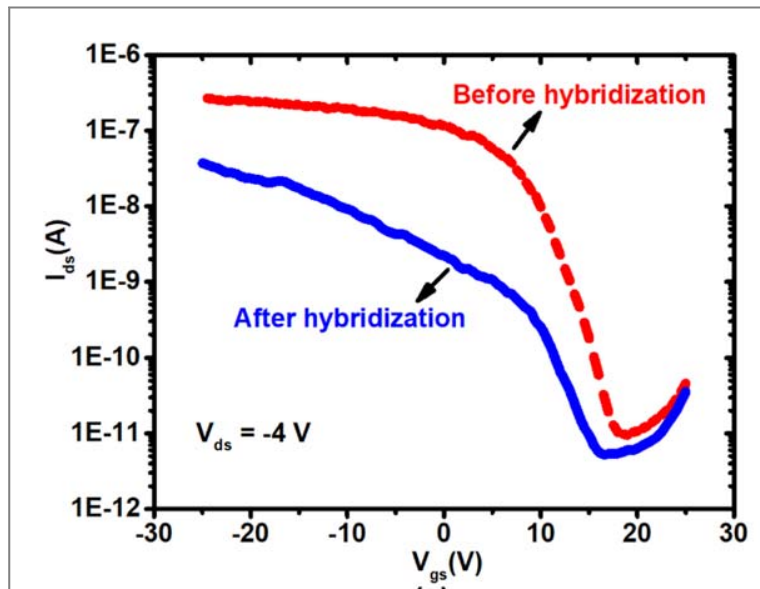

(a)

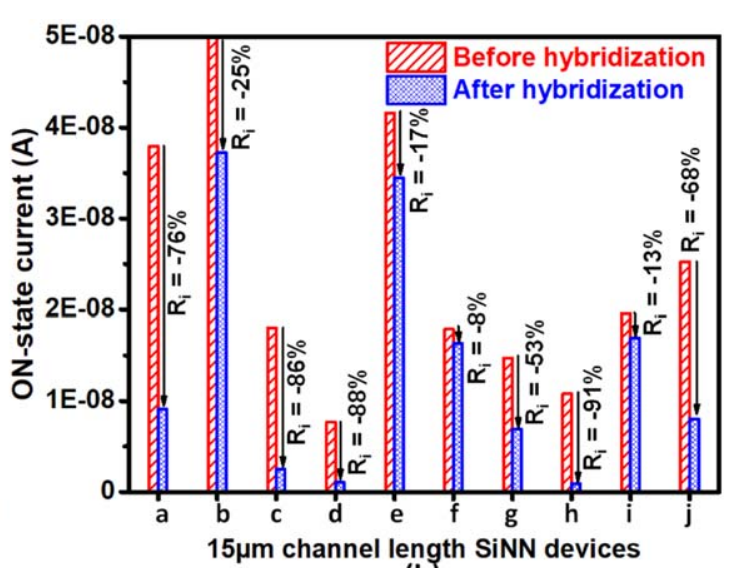

(b)

Figure 6. Electrical response of: (a) SiNN FET with L $=15 \mu \mathrm{m}$ before and after DNA hybridization, (b) ON-state current change of 10 devices with $\mathrm{L}=15 \mu \mathrm{m}$, the letter refers to the measured SiNN FETs.

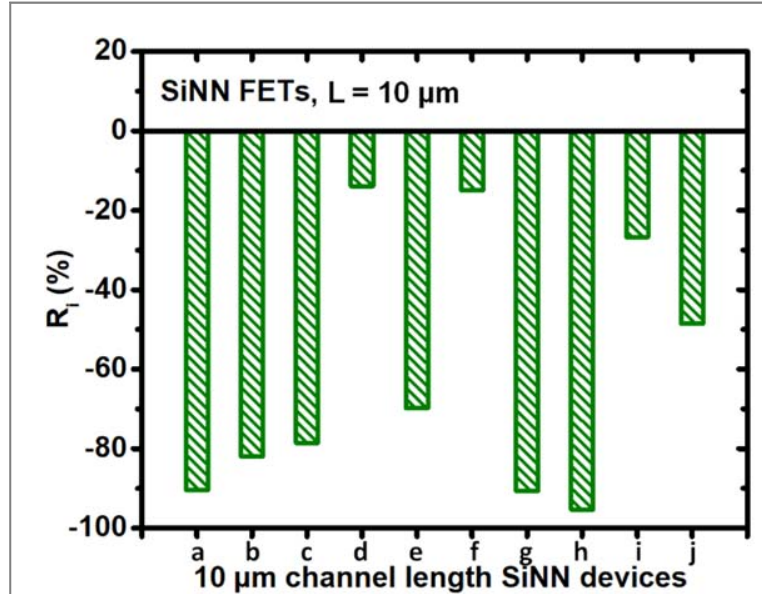

(a)

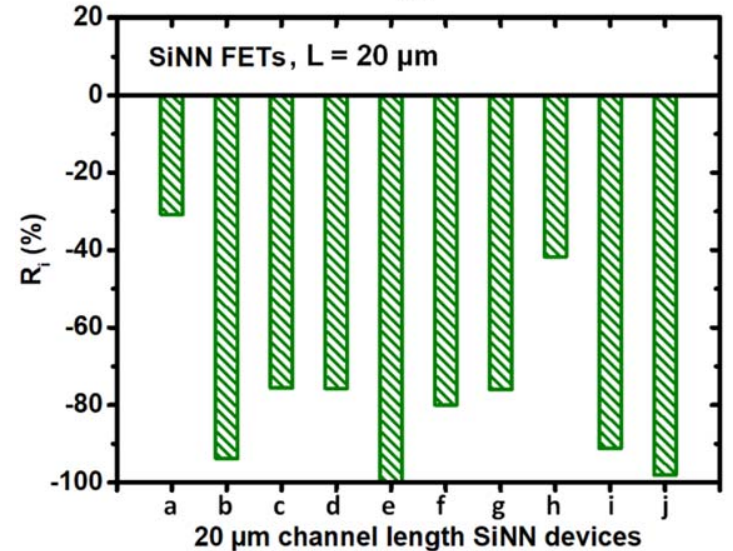

(c)

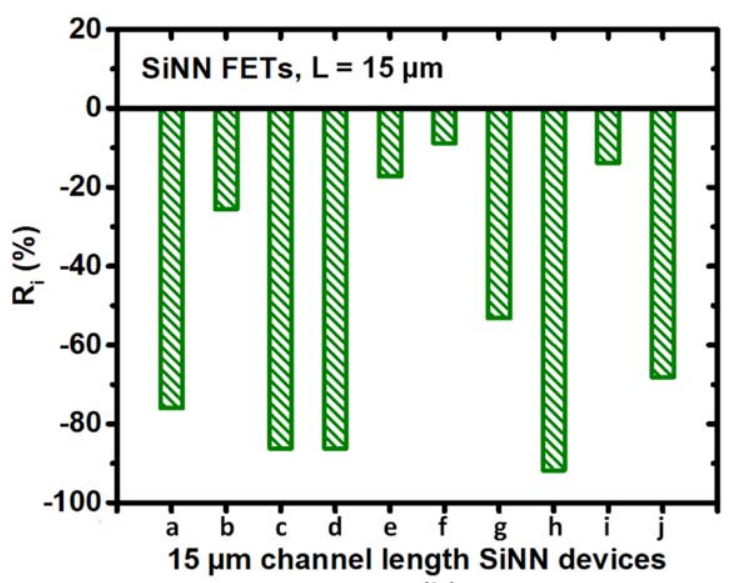

(b)

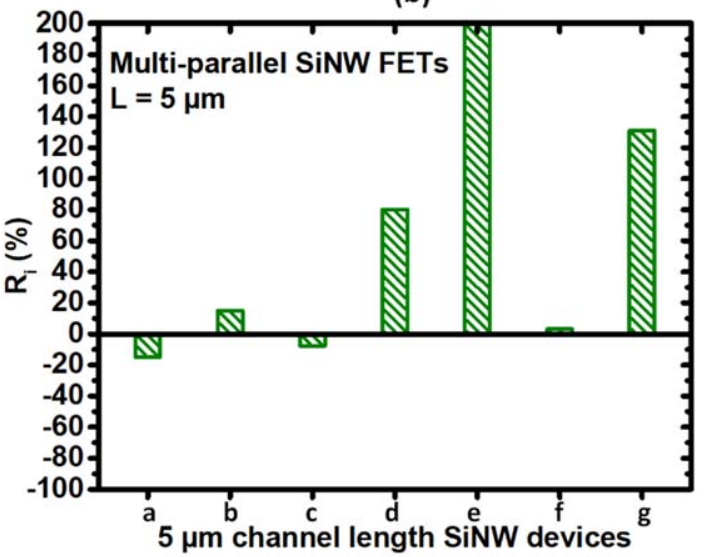

(d)

Figure 7. Relative variation of the ON-state current to DNA hybridization of: (a) $\mathrm{L}=10 \mu \mathrm{m}$; (b) $\mathrm{L}=15 \mu \mathrm{m}$; (c) $\mathrm{L}=20 \mu \mathrm{m}$; (d) $\mathrm{L}=5 \mu \mathrm{m}$; the letter refers to the measured FET.

devices with $\mathrm{L}=15 \mu \mathrm{m}$ show a systematic decrease of $\mathrm{I}_{\mathrm{ON}}$ upon hybridization (figure $6(\mathrm{~b})$ ). The sensitivity of our SiNN FETs to the DNA hybridization step can be thus confirmed. However, the reproducibility of these devices need to be improved in the future study regarding a significant variability of change between them.

In order to quantify the hybridization impact, we also extracted the relative ratio on ON-state current change upon hybridization, expressed as: 


$$
\left.\mathrm{R}_{\mathrm{i}}=(\mathrm{I}(\text { after hybridization })-\mathrm{I}(\text { before hybridization })) /(\mathrm{I} \text { (before hybridization })\right)
$$

as shown in figure 6(b).

As previously mentioned, transistors with $\mathrm{L}=5 \mu \mathrm{m}$ are considered multi-parallel nanowire devices whereas those with $\mathrm{L} \geqslant 10 \mu \mathrm{m}$ (e.g. 10,15,20 $\mu \mathrm{m}$ in this work) are nanonet-based ones. All these devices were studied as DNA sensors and the current changes, characterized by $\mathrm{R}_{\mathrm{i}}$, are reported in figure 7 . As one can see, all SiNN FETs (30/30 tested devices) with channel length ranging from 10 to $20 \mu \mathrm{m}$ exhibit a systematic and significant decrease, by more than $50 \%$ for most of them, with DNA hybridization. On the other hand, as shown in figure $7(\mathrm{~d}), \mathrm{MP}-\mathrm{SiNW}$ devices present a large dispersion in drain current variation $\left(\mathrm{R}_{\mathrm{i}}\right.$ from $-20 \%$ to $+200 \%)$. Moreover, the current increases on $4 / 7$ devices upon hybridization, which is not the case of SiNN. The SiNN devices clearly show more homogeneous and reproducible response to the DNA hybridization step as compared to MP-SiNW ones. We believe that this result originates from the averaging effect of electrical characteristics of nanonet. Further experiments, for instance by varying the NN density, are needed to explain more about these preliminary results and are in progress.

\section{Conclusion}

The fabrication of DNA sensing demonstrators based on field-effect silicon nanonet transistors has been reported. The devices exhibited interesting properties such as a high ON-state current, good $\mathrm{I}_{\mathrm{ON}} / \mathrm{I}_{\mathrm{OFF}}$ ratio and homogeneous electrical characteristics. For DNA sensing, a simple and eco-friendly functionalization process using GOPS allowed successful grafting of DNA probes at the nanonet surface. The DNA hybridization, clearly detected by fluorescence measurement, leads to a significant decrease in $\mathrm{ON}$-state current for all nanonet-based devices. Additionally, more reproducible current response to DNA detection was obtained in the case of nanonet devices as compared to multi-parallel nanowire-based ones. These first results confirm the advantages of nanonet FET devices and open the way to the label-free electrical detection of DNA and other strategic biomolecules.

\section{Acknowledgments}

This work has received funding from the EU H020 RIA project Nanonets2Sense under grant agreement $\mathrm{n}^{\circ}$ 688329 and partially supported by the LabEx Minos ANR-10-LABX-55-01. This work benefits from the facilities and expertise of the OPE)N(RA characterization platform of FMNT (FR 2542, supported by CNRS, Grenoble INP, UGA) and PTA (Upstream Technological Platform, co-operated by CNRS Renatech and CEA Grenoble, France).

\section{ORCID iDs}

Valérie Stambouli (ib https://orcid.org/0000-0003-0457-4119

Bassem Salem (iD https://orcid.org/0000-0001-8038-3205

Céline Ternon (10 https://orcid.org/0000-0001-8890-4239

\section{References}

[1] Ahmad R, Mahmoudi T, Ahn M-S and Hahn Y-B 2018 Recent advances in nanowires-based field-effect transistors for biological sensor applications Biosens. Bioelectron. $100312-25$

[2] Noor M O and Krull U J 2014 Silicon nanowires as field-effect transducers for biosensor development: a review Anal. Chim. Acta 825 $1-25$

[3] Serre P, Ternon C, Stambouli V, Periwal P and Baron T 2013 Fabrication of silicon nanowire networks for biological sensing Sensors Actuators B Chem. $182390-5$

[4] Acta A C, Zhang G-J and Ning Y 2012 Silicon nanowire biosensor and its applications in disease diagnostics: a review Anal. Chim. Acta $7491-15$

[5] Zhao Y and Grüner G 2012 Nanonet as a scaffold with targeted functionalities focuses on biocompatible nanoparticles for diag- nostics and therapeutics, porous materials for energy storage and catalysis, and nanocarbon-based electronics J. Mater. Chem. J. Mater. Chem 22 24983-91

[6] Lin Y-H, Lin W-S, Wong J-C, Hsu W-C, Peng Y-S and Chen C-L 2017 Bottom-up assembly of silicon nanowire conductometric sensors for the detection of apolipoprotein A1, a biomarker for bladder cancer Microchim. Acta 184 2419-28

[7] Veigas B, Fortunato E and Baptista P 2015 Field effect sensors for nucleic acid detection: recent advances and future perspectives Sensors 15 10380-98

[8] Chiang P et al 2012 Nanowire transistor-based ultrasensitive virus detection with reversible surface functionalization Chem.-An Asian J. 7 2073-9

[9] Ingebrandt S, Vu X-T, Eschermann J F, Stockmann R and Offenhausser A 2011 Top-down processed SOI nanowire devices for biomedical applications in ECS Transactions 35 3-15 
[10] Tian B, Xie P, Kempa T J, Bell D C and Lieber C M 2009 Single-crystalline kinked semiconductor nanowire superstructures Nat Nanotechnol. 4 824-9

[11] Regonda S, Tian R, Gao J, Greene S, Ding J and Hu W 2013 Silicon multi-nanochannel FETs to improve device uniformity/stability and femtomolar detection of insulin in serum Biosens. Bioelectron. 45 245-51

[12] Shalev G, Landman G, Amit I, Rosenwaks Y and Levy I 2013 Specific and label-free femtomolar biomarker detection with an electrostatically formed nanowire biosensor NPG Asia Mater. 5 e41-41

[13] Regonda S, Spurgin L and Hu W 2013 Ultrasensitive electronic detection of DNA using Si nanograting FETs coated with PNA probes 2013 13th IEEE Int. Conf. on Nanotechnology (IEEE-NANO 2013) 513-6

[14] Hahm J-I and Lieber C M 2004 Direct ultrasensitive electrical detection of DNA and DNA sequence variations using nanowire nanosensors Nano Lett. 451-4

[15] Zhao Y and Grüner G 2012 Nanonet as a scaffold with targeted functionalities J. Mater. Chem. 22 24983-91

[16] Ternon Cet al 2015 Low temperature processing to form oxidation insensitive electrical contact at silicon nanowire/nanowire junctions Adv. Electron. Mater. 1 1-8

[17] Serre P, Mongillo M, Periwal P, Baron T and Ternon C 2015 Percolating silicon nanowire networks with highly reproducible electrical properties Nanotechnology 2615201

[18] Gruner G 2006 Carbon nanotube films for transparent and plastic electronics J. Mater. Chem. 163533

[19] Ternon Cet al 2013 High aspect ratio semiconducting nanostructure random networks: highly versatile materials for multiple applications Phys. Status Solidi - Rapid Res. Lett. $7919-23$

[20] Serre P, Stambouli V, Weidenhaupt M, Baron T and Ternon C 2015 Silicon nanonets for biological sensing applications with enhanced optical detection ability Biosens. Bioelectron. 68 336-42

[21] Presnova Get al 2017 Biosensor based on a silicon nanowire field-effect transistor functionalized by gold nanoparticles for the highly sensitive determination of prostate specific antigen Biosens. Bioelectron. 88 283-9

[22] Demes-Causse T 2018 DNA grafting on silicon nanonets using an eco-friendly functionalization process based on epoxy silane Materials Today, Proc., Accepted

[23] Rosaz G et al 2011 High-performance silicon nanowire field-effect transistor with silicided contacts Semicond. Sci. Technol. 26 85020

[24] Legallais Met al 2018 An innovative large scale integration of silicon nanowire-based field effect transistors Solid. State. Electron. 143 97-102

[25] Gruner G 2005 Carbon nanotube transistors for biosensing applications Anal. Bioanal. Chem. 384 322-35

[26] Paska Y and Haick H 2009 Controlling properties of field effect transistors by intermolecular cross-linking of molecular dipoles Appl. Phys. Lett. 95233103 